\title{
Open Educational Resources Initiatives among North Carolina's Community Colleges
}

$\mathrm{I}$ n the early 2000's, the Open Educational Resources movement began with two separate but nearly simultaneous events: the launches of MIT's OpenCourseWare project and Creative Commons licenses. ${ }^{1}$ The basic idea was to share materials as widely and freely as possible for the benefit of all.

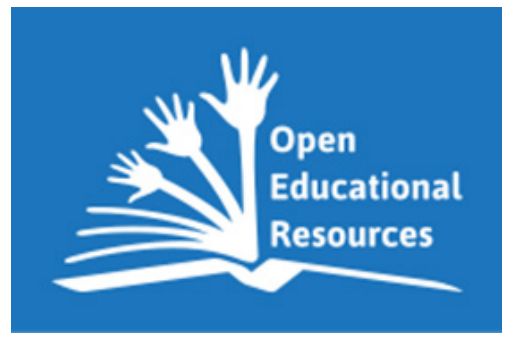

The term "Open Educational Resource" was adopted by UNESCO at a forum on higher education in developing countries, but the most-cited definition comes from the Hewlett Foundation: Open Educational Resources (OER) as those that are "made freely and legally available on the Internet for anyone to reuse, revise, remix and redistribute." 2 Four of these R's (reuse, revise, remix, and redistribute) are often joined by a 5th: retain, to describe the permissions common to open educational resources that make them available for current use and flexible enough to accommodate future use. ${ }^{3}$ These five R's are made explicit by the use of a license that builds on existing copyright laws. Creative Commons licenses are often used for this purpose.
As the name implies, the purpose of OER is to provide materials for teaching and learning. These materials can vary widely in type, from articles to books, from videos to software, or from ancillary materials like tests to whole courses. Research has shown that retention and student success are positively correlated with use of OER. ${ }^{4}$ OER initiatives have grown quickly over the last decade, providing funding and training for resource creation and adoption. Sometimes OER materials and outreach are coordinated by statewide initiatives like Affordable Learning Georgia and OpenOregon, aimed primarily at colleges and universities. In our home state, NCLIVE had a program from 2018 to early 2020 called Open Education North Carolina with a two-pronged focus: one was to provide OER for some of the most-taught courses in NC's public and private colleges and universities, and the other was to encourage adoption through workshops and adoption grants to faculty members. Funding for Open Education North Carolina was provided by the Institute of Museum and Library Services. ${ }^{5}$

Other significant OER initiatives are funded by governmental and private funders, including the Hewlett Foundation and the Saylor Academy. One important current program is the US Department of Education's \#GoOpen Initiative for K-12 schools. Our home state participates: the North Carolina Department of Public Instruction initiative called \#GoOpenNC provides

1 “Open Educational Resources," Wikipedia, last modified June 21, 2021, https://en.wikipedia.org/wiki/Open_educational_resources.

2 “Open Educational Resources: Breaking the Lockbox on Education,” William + Flora Hewlett Foundation, last modified November 26, 2013, https:// hewlett.org/open-educational-resources-breaking-the-lockbox-on-education/.

3 Wiley, David, "Defining the 'Open' in Open Content and Open Educational Resources," OpenContent.org, https:/opencontent.org/definition/.

4 See, for instance, Fischer, Lane, John Hilton, T. Jared Robinson, and David A. Wiley. "A Multi-Institutional Study of the Impact of Open Textbook Adoption on the Learning Outcomes of Post-Secondary Students." Journal of Computing in Higher Education 27, no. 3 (2015): 159-72. https://doi. org/10.1007/s12528-015-9101-x.

5 "Open Education North Carolina," NCLIVE, https://www.nclive.org/oenc. 
resources for teachers to implement in their local schools. ${ }^{6}$ At the university level, various public and private schools have programs, such as North Carolina State University's Open Education initiative, and at the UNC System level there is a collaborative Educational Resources Affordability Committee. ${ }^{7}$

OER initiatives have thus gained traction across educational levels, from K-12 to universities. Occupying a critical position in that educational continuum are community colleges. One of the best known community college OER programs is from Tidewater Community College in Virginia, which in 2013 began offering the first " $Z$ Degree" in the country. Z-Degree stands for "textbook-free" or zero textbook costs for students. After only four years, Tidewater was planning to launch additional $\mathrm{Z}$ Degrees not only to take advantage of student savings, but also because of gains in student retention and higher grades. ${ }^{8}$

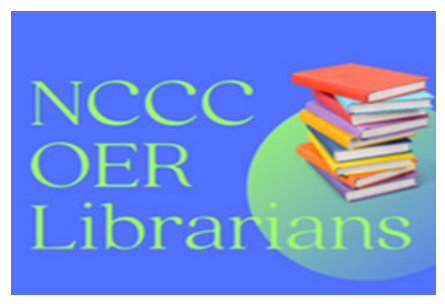

But did you know that North Carolina's community colleges are tackling OER too? One of the best places to start exploring NCCC's OER initiatives is openNCCC, which is available online at https://opennccc.nccommunitycolleges.edu/. OpenNCCC builds on more than a decade of shared resources, which began in 2007 with a learning object repository to share resources among the $58 \mathrm{com}$ munity colleges and grew into the North Carolina Learning Object Repository (NCLOR). Content from NCLOR was migrated to openNCCC in 2020, and additional content has been added. OpenNCCC's platform was created by OER advocate ISKME, which provides OER services, most notably the platform for OER Commons.

An initiative originating at the System Office, openNCCC's purpose is "to offer a comprehensive infrastructure that provides high-quality OER content and the opportunity for collaboration around the adaptation, evaluation, and instructional needs of faculty and learners." OpenNCCC currently contains more than 12,500 OER across all subject areas that faculty members are encouraged to use. The materials in openNCCC include syllabi, modules, and whole courses, as well as readings, case studies, assignments, and textbooks. In addition to these resources, openNCCC contains video tutorials on integrating content to the Learning Management System and authoring or remixing OER.

In addition to openNCCC, the North Carolina Community College Library Association (NCCLA) has also foregrounded open educational resources in professional development for members. The NCCLA Open Educational Resources Task Force was created in the spring of 2021 in the wake of a successful OER program during the NCCLA annual conference. ${ }^{10}$ Members of the Task Force are concentrating first on developing a sense of community in order to foster programs that all schools can build on. Another early goal of co-chairs Julie Reed and Garrison Libby is to create a guidebook or set of best practices that fellow librarians can turn to, in addition to having an identified community of practitioners who could offer advice.

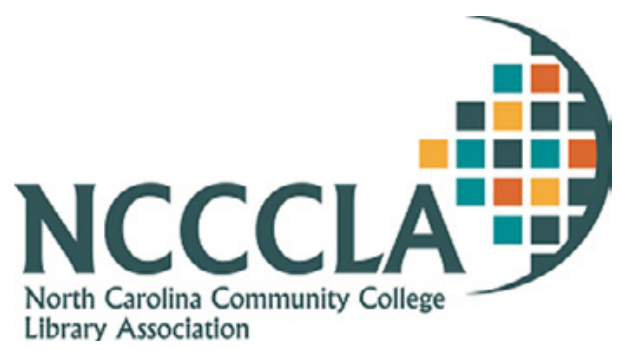

The Task Force members draw inspiration from each other and their colleagues as well as successful statewide programs like those in California, Oregon, and Colorado. ${ }^{11}$ Across our state, there are a variety of programs at individual community colleges that could serve as models. Among

6 “\#GoOpenNC," North Carolina Department of Public Instruction, https://sites.google.com/dpi.nc.gov/goopennc/.

7 “Open Education,” NC State University Libraries, https://www.lib.ncsu.edu/do/open-education; OER Initiatives ; UNC University Library Advisory Council, “Committees,” ULAC, last modified June 11, 2021, https://libguides.ecu.edu/c.php?g=671775\&p=4730382.

8 TCC Today, “Z-Degree adds up to $\$ 1$ million in savings plus student retention and better grades," Tidewater Community College, last modified October 3, 2017, https://news.tcc.edu/z-degree-reaches-one-million-savings/.

9 "About OpenNCCC," openNCCC, https://opennccc.nccommunitycolleges.edu/about.

10 “NCCCLA Conference 2021,” North Carolina Community College Library Association, https://ncccla.org/conferences/conference2021/; Davis, Angela, "NCCCLA OER Task Force,” NCCCLA, April 29, 2021, https://ncccla.org/2021/04/29/ncccla-oer-task-force/.

11 California Virtual Campus, "Open Educational Resources," California Community Colleges, https://cvc.edu/open-educational-resources/; “OpenOregon Educational Resources,” OpenOregon, https://openoregon.org/; CCCOnline, “Colorado OER Council,” Colorado Department of Higher Education, http://masterplan.highered.colorado.gov/oer-in-colorado/. 
them are online faculty development courses such as those offered at Wake Tech, or the OER Course Development grants offered by Central Carolina Community College. ${ }^{12}$ Another success story comes from Central Piedmont Community College, where English 112 courses fully utilize OER, and Biology 110 and 111 are actively integrating OER.

Most recently, NCCCLA hosted an OER Panel Discussion on July 8, 2021, with panelists Samantha O'Connor (Central Carolina), Julie Reed (Central Piedmont), Liza Palmer (Brunswick), and Stephen Brooks (Durham Tech), with moderator Garrison Libby (Central Piedmont). The panelists discussed OER experiences at their institutions, including the strategies they employed working with departmental faculty to adopt and use OER in their classes. Panelists and attendees shared some of the challenges community college faculty and librarians face when considering Open Educational Resources. Among them are the fact that many courses are taught by adjunct faculty who are pulled in many directions, so having a "plug and play" solution like commercial textbook companies offer is a powerful attractant. Many of the currently-available OER do not yet have ancillary materials like slides, homework, or quizzes, and developing them or finding alternatives is time-consuming. Another issue that continues to linger for some faculty members is a concern over quality, despite increasing research and the availability of reviews of OER such as the ones available on Open Textbook Library. Librarians are trying to work with faculty members to address these issues by identifying high quality materials they can use, or encouraging them to create new materials that can aid other faculty members in their discipline.

For community college students, textbook costs are not an abstract problem. Julie Reed recalled a time recently when she attended a Student Government Association meeting and asked who there had chosen not to buy a textbook before. All hands went up. There are some times when students have to choose between buying groceries and buying the required books for their classes. There are some times when the textbook cost is higher than the cost of taking the class. Ultimately, these are solvable problems, and Open Educational Resources are part of the solution. As partners with students and with faculty, librarians are also part of the solution.

12 eLearning Support and Instructional Design, “Online Faculty Development,” Wake Tech, https://waketech.edu/elsid/faculty-development; Center for Academic Excellence, "OER Course Development Opportunities," Central Carolina Community College, https://www.cccc. edu/teaching-learning/awards/course-development-oer/.
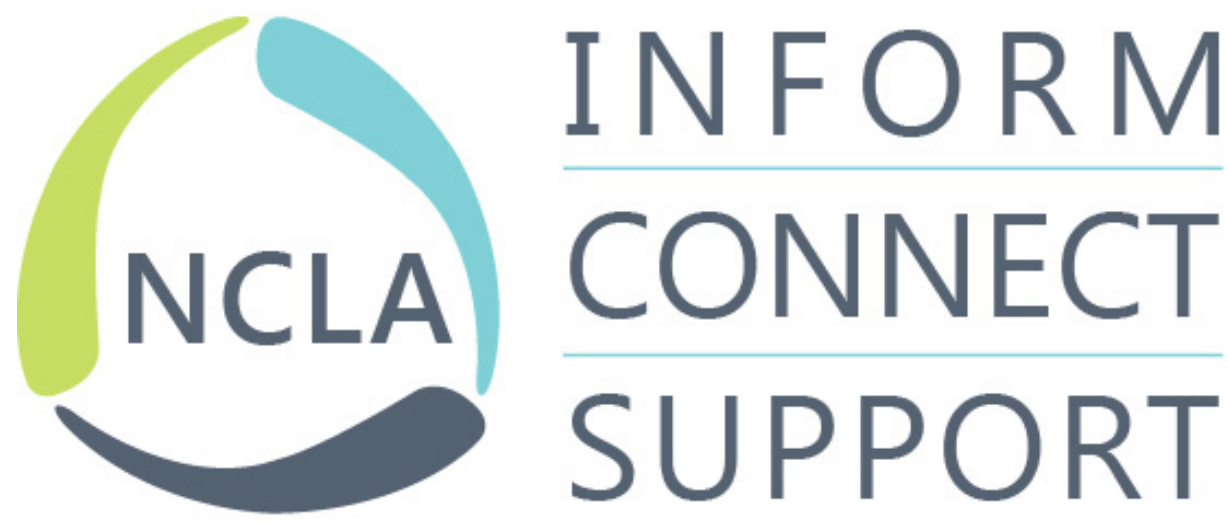